\title{
Aspectos que inciden en la inadecuada política criminal del Estado del Sistema Penitenciario Colombiano durante los últimos años*
}

\author{
Issues affecting the inadequate criminal justice policies of the \\ Colombian prison system in recent years \\ Questões que afectam as inadequadas políticas de justiça criminal \\ do sistema prisional colombiano nos últimos anos
}

Revista LOGOS CIENCIA \& TECNOLOGÍA ISSN 2145-549X

Vol. 4. No. 1, Julio - Diciembre, 2012, pp. 169-180

\section{Resumen}

En Colombia la crisis del Sistema Penitenciario es profunda, pues se ve alterada por la ineficacia de las políticas criminales que el Estado instaura. Mas allá de los altos índices de criminalidad que Colombia maneja en

\section{Fecha de Recepción: 17 de febrero de 2012 \\ Fecha de Aceptación: $\mathbf{1 0}$ de mayo de $\mathbf{2 0 1 2}$}

El presente artículo es resultado del Grupo de Investigación en Derechos Humanos Antonio Nariño y Álvarez, Registro de Colciencias COL53849, Categoría B. 2010.

** Abogada y Magistrando de Criminología y Victimología de la Facultad de Ciencias Jurídicas de la Dirección de Escuelas de la Policía Nacional de Colombia. Experiencia de nueve años en los Grupos de Investigación "Derecho Penal, Criminología, Política Criminal César Bkria" de la Universidad Autónoma de Colombia y la Policía Nacional de Colombia. "Derechos Humanos Antonio Nariño y Álvarez" de la Universidad Pedagógica Nacional, Universidad Autónoma de Colombia, Universidad Francisco José de Caldas. "El Alba de los Derechos Humanos" de la Universidad Autónoma de Colombia, todos reconocidos y categorizados en Colciencias.

*** Abogado de la Universidad Libre, Especialista en Derechos Humanos Escuela Superior de Administración Pública -ESAP- Especialista en Derecho Penal y Criminología Universidad Externado de Colombia. Magister en Derecho Penal Universidad Libre y Ph.D. (c) en Derecho Universidad Alfonso X El Sabio. la actualidad, son las violaciones de Derechos Humanos y la crisis que dentro de los Centros Penitenciarios se vive en la actualidad en detrimento al sentido de resocialización el cual es el objetivo del Sistema.

Palabras Claves: Sistema Penitenciario, cárcel, procesado, resocialización, criminalidad, Derechos Humanos.

\section{Abstract}

In Colombia the crisis is deep prison system, as altered by the ineffectiveness of the criminal policies that the State establishes. Beyond the high crime rates that currently handles Colombia, are the violations of Human Rights and the crisis in the prisons are currently living in detriment to the sense of rehabilitation which is the goal of the system.

Key Work: Prison system, prison, processed, resocialization, crime, Human Rights

\section{Resumo}

Na Colômbia, a crise é profunda sistema prisional, conforme alterada pela ineficácia das políticas criminosas que o Estado estabelece. Além dos altos índi- 
ces de criminalidade que atualmente lida Colômbia, são as violações dos Direitos Humanos e da crise nas prisões estão vivendo atualmente em detrimento do sentido da reabilitação que é o objetivo do sistema.

Palavras chave: Sistema prisional, prisão, processados, ressocialização, crime, Direitos Humanos

\section{INTRODUCCIÓN}

En Colombia los altos índices de violaciones a los Derechos Humanos, no solo radican en el contexto del Conflicto Armado Interno y en zonas de mayor

La crisis del sistema penitenciario ha conllevado un sinnúmero de procesos jurídicos, pues las garantías de educación y trabajo dentro de las cárceles, ha sido casi nula, debido a los problemas de financiación y hacinamiento que dichos establecimientos enfrentan.

列

casi nula, debido a los problemas de financiación y hacinamiento que dichos establecimientos enfrentan.

\section{METODOLOGIA}

El problema de investigación se desarrolla a partir de la revisión de la crisis del Sistema Carcelario y Penitenciario como fenómeno criminal dentro del contexto colombiano de manera cualitativa, la cual utilizó bases cuantitativas resultados de estudios obtenidos por entes como el INPEC ó estudios realizados por el Doctor Anitua.

\section{Aspectos Generales}

Retrocediendo un poco en el tiempo, se dilucida que la prisión o el sistema en general fue establecido como una forma de castigo creado en el Siglo XVIII, el cual ha ido transformándose dependiendo de la cultura, necesidad y/o modernidad de los países. Durante el transcurso de la historia la Cárcel diferentes tratadistas y juristas de manera materialista o filosófica han incursionado en el tema del origen carcelario de forma profunda, por ejemplo para Melossi y Pavarini, fue creada por el Estado como una gran empresa, donde los trabajadores eran los prisioneros. $Y$ en el ámbito filosófico se encuentra Michel Foucault, de quien Anitua (2011) asevera lo siguiente:

"Michel Foucault ha indicado la necesaria relación entre la prisión, como ejemplo privilegiado de la nueva tecnología que impondrá una sociedad disciplinaria, y las libertades que también inaugura el pensamiento de las luces".

En el sistema penitenciario colombiano es el Estado quien establece el sistema penal y en sus respectivas jurisdicciones, sobre la base del trabajo, su capacitación para el mismo y la educación como medios de resocialización del infractor de la ley. Está basado en principios sobre los problemas que originaron las leyes en cuanto a las diferentes reformas carcelarias, las cuales buscan una reacción contra el hacinamiento, educación, alimentación, trabajo, higiene, promiscuidad y la rehabilitación de los internos.

Cabe entonces preguntarse por qué en Colombia estando provista de 144 Establecimientos Penitenciarios segregados a lo largo del país dentro de los 
cuales se diferencian los Establecimientos Penitenciarios de Alta, Mediana y Mínima Seguridad, Reclusión de Mujeres, Colonias Agrícolas y demás, hay vulneraciones a los Derechos Humanos y un quebrantamiento al principio reconocido internacionalmente como es la Dignidad Humana.

Aquí vale la pena hacer una breve explicación sobre la situación actual en Colombia, según el Informe de las Naciones Unidas (2011):

"En Colombia el índice de hacinamiento es de 41.7\%. Un hacinamiento crónico muy alto que constituye por sí sólo un factor de violación de los derechos (...) imposibilita la convivencia pacífica entre los internos $y$ les exige soportar condiciones de vida violatorias de su dignidad. (...) Eduardo Cifuentes, ponente de la sentencia que mostró la sistemática y alarmante violación de derechos fundamentales en las cárceles [expresa]: 'durante las inspecciones judiciales realizadas a múltiples cárceles fue necesario suspender las diligencias en la noche, ante la imposibilidad de caminar sin pisar las cabezas de los reclusos que estaban acostados en el suelo.' En penales como La Picota o Jamundí, 'la luz solar no entra ni siquiera por un tiempo limitado.' Hecho reconocido por el CDH como constitutivo de una violación de la dignidad. El hacinamiento también ha sido denunciado por instituciones internacionales y Gobiernos extranjeros. La Oficina del Alto Comisionado de la ONU para los Derechos Humanos ha advertido que los prisioneros sufren malos tratos y hacinamiento. Las condiciones en que viven los presos en Colombia fueron tenidas en cuenta por el Tribunal Europeo de Derechos Humanos para negar la extradición de una persona solicitada por las autoridades colombianas. De acuerdo con el Tribunal Europeo, el prisionero corría alto riesgo de ser objeto de malos tratos durante su detención, producto de las malas condiciones y de los abusos por parte de la guardia.(...).

Con respecto a las condiciones de salubridad existen serios problemas relacionados con el suministro de agua y la falta de higiene de los espacios comunales. La deficiente infraestructura trae problemas en el control de enfermedades infectocontagiosas y plagas. La Procuraduría denunció esta situación, diciendo que los penales se han convertido en cunas para 'el desarrollo de enfermedades infecto-contagiosas como tuberculosis, lepra, varicela, hepatitis $A$, hepatitis $B, V I H$, sífilis, gonorrea y otras enfermedades de transmisión sexual, así como para infestaciones por vectores de plaga".

En el Informe alternativo sobre la tortura, tratos crueles, inhumanos o degradantes, Colombia 2003-2009, presentado por la Coalición Colombiana contra la Tortura al Comité contra la Tortura de las Naciones Unidas (2009, 32), presenta de manera estadística las violaciones de Derechos Humanos a los cuales los prisioneros eran sometidos mediante entrevistas realizadas en los Establecimientos Penitenciarios y las cuales dieron el siguiente resultado:

Según la oficina de control disciplinario interno del INPEC, desde enero del 2007 a junio de 2008 ha registrado 79 faltas disciplinarias documentadas de maltrato físico y verbal en contra de las y los internos. Entre ellas destacan: fracturas, golpes, aplicación del escorpión (esposado de manos y pies), amenazas de muerte, obligación a desnudarse, no permitir atención médica, acoso sexual, agresión y maltrato verbal a los visitantes. La mayoría de los casos han sido remitidos por competencia y solo en dos se ha abierto una investigación disciplinaria, lo cual evidencia el alto nivel de impunidad.

Por su parte, la Procuraduría ha registrado $198 \mathrm{ca}$ sos en contra de funcionarios del INPEC entre enero de 2007 y abril de 2008, entre otros, por diferentes categorías de trato inhumano, cruel y degradante.

El Comité de Solidaridad realizó una encuesta entre abril y junio de 2008, a la que el 54\% (125/230) de los internos respondió sí a la pregunta de si habían sido torturados alguna vez. Es notable que el $46 \%$ (106/230) de la población no diera respuesta a la pregunta, tal vez por el posible temor a represalias.

El 86\% (198/230) de las personas encuestadas respondió sí a la pregunta de si habían sido víctimas de tortura psicológica en alguna oportunidad dentro de la cárcel. Las modalidades de tortura psicológica usadas en los centros penitenciarios consisten en: aislamiento, amenazas, presión sobre familiares y ejecuciones simuladas. En muchos casos, estas for- 
mas de tortura son combinadas en contra de una misma persona. Los responsables de estos actos de tortura son en su mayoría las guardias y funciona-

No se debe

olvidar que las

personas privadas

de la libertad,

por el hecho de

cometer infracción

en contra de la

ley, no pierden

sus derechos

fundamentales.

rios del INPEC, aunque tam-

bién hay casos en donde el ejército y policía han perpetrado las violaciones.

Es prudente advertir que la vulneración a los Derechos Humanos de las personas privadas de su libertad siendo condenadas o procesadas va en crecimiento, debido a factores de sometimiento por parte del Estado, abarcando la integridad física mediante enfrentamiento por parte de los funcionarios con los reos y debido a la situación de hacinamiento que legitima la compleja vulnerabilidad del Estado en cuanto al recurso financiero y físico que propende la escasa oportunidad de educación y trabajo como parte fundamental del proceso de resocialización.

No se debe olvidar que las personas privadas de la libertad, por el hecho de cometer infracción en contra de la ley, no pierden sus derechos fundamentales, por el contrario internacionalmente están resguardados por las diferentes Convenciones Internacionales y pactos que propenden una protección especial evitando un resquebrajamiento de sus derechos frente a las personas que se encuentran fuera del sistema judicial, logrando unas garantías formales y un reconocimiento como persona a la cual le son inherentes los Derechos Humanos.

En relación con lo anterior, menciona Martínez (1995, 34), cuando trabajamos por los derechos fundamentales de las personas privadas de la libertad, debemos liberarnos de un prejuicio del que son prisioneras las tendencias de la denominada "opinión pública"; aquellas que consideran a los prisioneros o incluso a los simplemente procesados como seres diversos o patológicamente anormales y que por tanto deben ser "tratados" o "ayudados".

No podemos dejar de lado la evolución que ha tenido en América Latina la criminalidad y por ende el uso del sistema carcelario en los diferentes países. En este contexto Anitua $(2011,134)$ presenta de forma gráfica dicho progreso de incremento (o decremento) frente a los años 1992 a 2007:

\begin{tabular}{|l|r|r|r|}
\hline \multicolumn{1}{|c|}{ PAÍSES LATINOAMERICANOS } & $\begin{array}{c}\text { POBLACIÓN RECLUSA A } \\
\mathbf{1 9 9 2}\end{array}$ & $\begin{array}{c}\text { POBLACIÓN RECLUSA EN } \\
\text { LA ACTUALIDAD (Según } \\
\text { Datos) }\end{array}$ & $\begin{array}{c}\% \\
\text { INCREMENTO }\end{array}$ \\
\hline Argentina & 21.016 & 60.621 & $188 \%$ \\
\hline Bolivia & $5.412(1996)$ & 7.682 & $269 \%$ \\
\hline Brasil & 114.377 & 422.590 & $133 \%$ \\
\hline Chile & 20.989 & 48.855 & $96 \%$ \\
\hline Colombia & 33.491 & 65.772 & $58 \%$ \\
\hline Ecuador & 7.998 & 12.635 & $106 \%$ \\
\hline Paraguay & $2.972(1995)$ & 6.115 & $166 \%$ \\
\hline Perú & 15.718 & 41.745 & $129 \%$ \\
\hline Uruguay & 3.037 & 6.947 & $-5 \%$ \\
\hline Venezuela & $23.200(1993)$ & 22.000 & $154 \%$ \\
\hline México & 85.712 & 217.457 & \\
\hline
\end{tabular}

\subsection{El hacinamiento}

En contraste con el objetivo de las políticas penitenciarias y carcelarias de prevención, cumplimiento de la ley, rehabilitación y reinserción social, la situación actual es denigrante para los procesados, por cuanto las cárceles colombianas son realizadas in- fraestructuralmente para un determinado número de personas pero en la realidad ese número es superado casi en su integralidad existiendo así una sobrepoblación carcelaria definiendo una precariedad de condiciones mínimas necesarias de los privados de la libertad. 
Estableciéndose este como uno de los factores predominantes que interrumpen la actividad de resocialización de los procesados, el hacinamiento perjudica íntegramente la Dignidad Humana y fortalece el camino de la criminalidad, por cuanto es generado dentro de un ambiente malsano de drogadicción por falta de eficacia en la intromisión de sustancias ilegales, una falencia en los elementos sustanciales para una minimización de la problemática.

Es significativo establecer que en el momento en que el Estado como Política Criminal determinó la ampliación de cupos en las cárceles para evitar así el hacinamiento, no fueron tomadas en cuenta las condiciones al momento de su implementación. Esto quiere decir que cuando se asignaron los cupos, estos fueron utilizados por los miembros de las AUC, quienes primeramente no estaban dentro del cálculo de procesados, por ende fue insuficiente su conformación inicial.

También cabe mencionar mediante las estadísticas generales anuales de 2012 que presentó el INPEC a fecha de 30 de septiembre de 2012 los siguientes datos:

\begin{tabular}{|l|c|c|c|}
\hline REGIONAL & CAPACIDAD & $\begin{array}{c}\text { TOTAL } \\
\text { POBLACIÓN }\end{array}$ & HACINAMIENTO \\
\hline $\begin{array}{l}\text { REGIONAL } \\
\text { CENTRAL }\end{array}$ & 28.475 & 37.971 & $33,3 \%$ \\
\hline $\begin{array}{l}\text { REGIONAL } \\
\text { OCCIDENTE }\end{array}$ & 14.414 & 21.850 & $51,6 \%$ \\
\hline $\begin{array}{l}\text { REGIONAL } \\
\text { NORTE }\end{array}$ & 7.180 & 12.170 & $69,5 \%$ \\
\hline $\begin{array}{l}\text { REGIONAL } \\
\text { ORIENTE }\end{array}$ & 7.124 & 11.940 & $67,6 \%$ \\
\hline $\begin{array}{l}\text { REGIONAL } \\
\text { NOROESTE }\end{array}$ & 8.414 & 15.428 & $83,4 \%$ \\
\hline $\begin{array}{l}\text { REGIONAL } \\
\text { VIEJO CALDAS }\end{array}$ & 10.069 & 13.745 & $36,5 \%$ \\
\hline TOTAL MES & 75.676 & 113.104 & $49,5 \%$ \\
\hline
\end{tabular}

Fuente: http://www.inpec.gov.co/portal/page/portal/Inpec/ SeccionInpeccomoinstitucion/Consolidado_estadistico La Gráfica ha sido modificada por el Autor.

\subsection{Salubridad pública}

Hay que reconocer que a la luz del hacinamiento junto a él podemos dilucidar el problema de la salubridad pública. En tanto hay sobrepoblación carcelaria, falta de garantías por parte del Estado y déficit financiero, los servicios públicos se ven restringidos y disminuidos para la eficacia en la entrega de dicho derecho.
Las Naciones Unidas dentro de las Reglas Mínimas del Tratamiento de Reclusos, las cuales contienen de manera específica las garantías necesarias establecidas para que la entidad que el Estado comisione resguarde a los procesados aquellos derechos de los cuales son inherentes, menciona que:

"sin hacer diferencias de raza, color, sexo, En el momento en que el Estado como Política Criminal determinó la ampliación de cupos en las cárceles para evitar así el hacinamiento, no fueron tomadas en cuenta las condiciones al momento de su implementación. lengua, religión, opinión política o cualquier otra opinión, de origen nacional o social, fortuna, nacimiento $u$ otra situación cualquiera, tienen derecho a ciertas condiciones mínimas, que les permitan disfrutar de una vida verdaderamente digna y humana. En concreto, la declaración hace referencia a las condiciones mínimas en que se deben encontrar los espacios destinados para uso de los reclusos, especialmente, el espacio destinado para dormir y las instalaciones sanitarias; el acceso a ropa y ropa de cama; a una adecuada alimentación cuyo valor nutritivo sea suficiente para el mantenimiento de su salud y de sus fuerzas; al agua potable para el consumo; a ejercitarse físicamente; a recibir servicio médico calificado, y al trabajo".

Comoquiera que lo anterior se encuentra internacionalmente establecido, la precariedad de los servicios públicos en Colombia es mínima, pues con el gran número de presos el solo servicio del agua potable se ve disminuido, como se demuestra en la Sentencia T-639 de 2004, la cual aduce que:

"el deber de suministro de agua potable, en el marco de la relación de especial sujeción, exigía un suministro continuo del servicio público de agua potable, pues de ello dependía la satisfacción de otros derechos como la alimentación, el aseo personal, el mantenimiento de condiciones sanitarias higiénicas aceptables, etc., que a su vez repercutían en la dignidad de la población carcelaria. Por lo tanto, concluyó que las empresas de servicios públicos tenían derecho a ejercer los medios coactivos a su dispo- 
sición, pero no podían suspender el suministro de agua".

Y en 2006 la Sentencia T- 317, sobre el mismo sostuvo que:

"el derecho a contar con unas condiciones mínimas de existencia también implicaba el derecho a tener suficiente agua potable, no sólo para el consumo, sino también para disfrutar de un entorno higiénico. Incluso señaló la Sala que si el deber de mantener los sanitarios aseados le corresponde a un determinado grupo de reclusos, y los mismos no cumplen con ese deber, es la institución carcelaria la encargada de tomar los correctivos que correspondan con el fin de arreglar la situación".

\subsection{Derecho a la salud}

En este punto, la discusión de la violación de De-

La Corte Interamericana

de Derechos Humanos

fallo en contra del

estado peruano por

el reconocimiento

de violación al

Derecho a la Vida, Integridad personal

de los fallecidos y por

violación a la integridad

personal, garantías

judiciales y protección

judicial

En cuanto al acceso a los servicios de salud, la Corte ha reiterado que en cumplimiento de las obligaciones que se derivan de la relación de especial sujeción, la salud debe considerarse como un derecho que no puede suspenderse. En consecuencia, todos los reclusos de los establecimientos penitenciarios y carcelarios tienen derecho a que el Estado les garantice el acceso a los servicios de salud que requieran, prestados bien sea por la unidad de sanidad dentro del establecimiento o por la entidad promotora de salud contratada para tales fines. En concreto, en la Sentencia T-744 de 2009 se protegió el derecho a la salud de un recluso del Establecimiento Penitenciario de Alta y Mediana Seguridad de Girón, Santander, que de acuerdo a dictamen de los médicos que lo atendieron en sanidad de la institución, sufría trastornos psiquiátricos y debía ser remitido a una unidad de salud mental por fuera del establecimiento, para recibir el tratamiento adecuado a su enfermedad. Reiteró en esa oportunidad la Sala Cuarta de Revisión, lo que aquí se ha sostenido y dijo:

"Is]iguiendo esa línea interpretativa, tal y como se expuso, existe un grupo de derechos de los reclusos que no están limitados, por causa de la privación de la libertad de la que son objeto. Tal es el caso del derecho a la salud, el cual, gracias a su estrecha relación con el derecho a la vida y a la dignidad humana, permanece incólume frente a su situación, lo que necesariamente implica que durante el periodo dentro del cual se prolongue la reclusión, le corresponde al Estado garantizar el acceso a los servicios que requieran los internos en la materia. [...] De la lectura de las normas citadas, se puede concluir, que el Estado tiene la obligación de garantizar que los reclusos tengan acceso al servicio de salud cuando lo requieran, lo cual se explica en la imposibilidad en la que se encuentran, por cuenta de la privación de la libertad, para afiliarse a uno de los regímenes en salud previstos en el Sistema General de Seguridad Social, o para acudir a una institución médica de naturaleza pública o privada, en procura de la atención para sus enfermedades o dolores, razón por la cual, los internos dependen, única y exclusivamente, de los servicios de salud que, para ese efecto, el Sistema Penitenciario y Carcelario les proporcionen".

\section{Sentencia Castro Castro contra Perú}

Los hechos ocurridos entre el 6 y 9 de Mayo de 1992, consistieron en la eliminación de las mujeres y hom- 
bres acusados por el delito de Terrorismo, en el cual los agentes de policía se valieron de armas y estrategias de guerra, donde fueron vulnerados los Derechos Humanos de personas rendidas y desarmadas con base en la tortura, actos sexuales y constantes bombardeos. Como resultado se dio muerte a 41 internos, 185 personas quedaron heridas, sin embargo, fueron trasladadas a otros penales bajo la orden que permanecieran totalmente incomunicadas.

Se inició una investigación a la Policía, quedando esta archivada bajo consideración de que fueron hechos resultado del servicio y en función del cumplimiento de la Ley.

Ante la $\mathrm{CIDH}$ fue presentada la demanda por violación de los Derechos Humanos el 18 de mayo de 1992 y el 5 de junio de 1997. Luego de la investigación pertinente 14 años después de los hechos, el 25 de noviembre de 2006, la Corte Interamericana de Derechos Humanos falló en contra del Estado peruano por el reconocimiento de violación al Derecho a la Vida, integridad personal de los fallecidos y por violación a la integridad personal, garantías judiciales y protección judicial contra los 185 heridos que sobrevivieron a dicho ataque.

Esta sentencia ha sido a nivel mundial un precedente, pues presenta un avance en cuanto a las garantías y el respeto de los derechos de las personas privadas de la libertad y en cabeza del Estado, como lo establece la Corte en la siguiente consideración:

238. En razón de lo anterior, los Estados deben adoptar las medidas necesarias no sólo para prevenir y castigar la privación de la vida como consecuencia de actos criminales, sino también para prevenir las ejecuciones arbitrarias por parte de sus propias fuerzas de seguridad, situación que se ve agravada cuando existe un patrón de violaciones de los derechos humanos. De manera especial, los Estados deben vigilar que sus cuerpos de seguridad, a quienes les está atribuido el uso de la fuerza legítima, respeten el derecho a la vida de quienes se encuentren bajo su jurisdicción.

239. Como se desprende de los "Principios Básicos sobre el Empleo de la Fuerza y de Armas de
Fuego por parte de Oficiales Encargados de Hacer Cumplir la Ley", los cuerpos de seguridad estatales solamente pueden recurrir al empleo de armas letales cuando sea "estrictamente inevitable para proteger una vida" y cuando resulten ineficaces medidas menos extremas.

240. Como lo ha señalado en ocasiones anteriores, esta Corte reconoce la existencia de la facultad e incluso la obligación del Estado de garantizar la seguridad y mantener el orden público, en especial dentro de las cárceles, utilizando la fuerza si es necesario. Al respecto, también ha establecido que al reducir alteraciones al orden público el Estado debe hacerlo con apego y en aplicación de la normativa interna en procura de la satisfacción del orden público, siemLos Estados deben vigilar que sus cuerpos de seguridad, a quienes les está atribuido el uso de la fuerza legítima, respeten el derecho a la vida de quienes se encuentren bajo su

jurisdicción.

pre que esta normativa $y$

las acciones tomadas en aplicación de ella se ajusten, a su vez, a las normas de protección de los derechos humanos aplicables a la materia. El poder estatal no es ilimitado; es preciso que el Estado actúe "dentro de los límites y conforme a los procedimientos que permiten preservar tanto la seguridad pública como los derechos fundamentales de la persona humana". En casos que esta Corte ha conocido en los que el Estado ha utilizado la fuerza para mantener el orden dentro de centros penales cuando se presenta un amotinamiento, cosa que no sucedió en el presente caso, el Tribunal ha analizado si existían elementos suficientes para justificar la magnitud de la fuerza utilizada.

Igualmente la Corte realiza consideraciones respecto a los sobrevivientes de los hechos ocurridos en 1992 por violación a su integridad física, aludiendo que:

293. Con base en lo indicado anteriormente, este Tribunal considera que el Estado es responsable de la violación a la integridad física de los internos que resultaron heridos durante los hechos del 
6 al 9 de mayo de 1992, lo cual constituyó una violación al artículo 5 de la Convención Americana. Asimismo, la Corte considera que, en las circunstancias del presente caso, el conjunto de actos de agresión y las condiciones en que el Estado puso deliberadamente a los internos (los que fallecieron y los que sobrevivieron) durante los días del ataque, que causaron en todos ellos un grave sufrimiento psicológico y emocional, constituyó una tortura psicológica inferida en agravio de todos los miembros del grupo, con violación de los artículos 5.1 y 5.2 de la Convención Americana, y 1, 6 y 8 de la Convención Interamericana para Prevenir y Sancionar la Tortura. Además, esta Corte estima que la violación del derecho a la integridad personal de las señoras Eva Challco, Sabina Quispe Rojas y Vicenta Genua López se vio agravada por el factor de que se encontraban embarazadas, de forma tal que los actos de violencia les afectaron en mayor medida. Igualmente, la Corte considera que el Estado es responsable por los actos de tortura infligidos a Julia Marlene Olivos Peña, con violación del artículo 5.2 de la Convención Americana y de los artículos 1, 6 y 8 de la Convención Interamericana para Prevenir y Sancionar la Tortura.

Como reparación a los daños perpetrados por las fuerzas policiales a las víctimas del flagelo cometido hacia ellos, la Corte estableció una reparación la cual consta principalmente de:

1. Sancionar a los responsables de los hechos.

2. Asegurar que los restos de las personas fallecidas sean entregados a sus familiares.

3. Realizar una ceremonia pública como desagravio a los familiares de las víctimas.

4. Asistir psicológica y médicamente a las víctimas directas e indirectas de los hechos.

5. Realizar un monumento a las víctimas llamado "El Ojo que Llora".

6. Demás reparaciones monetarias a las víctimas.

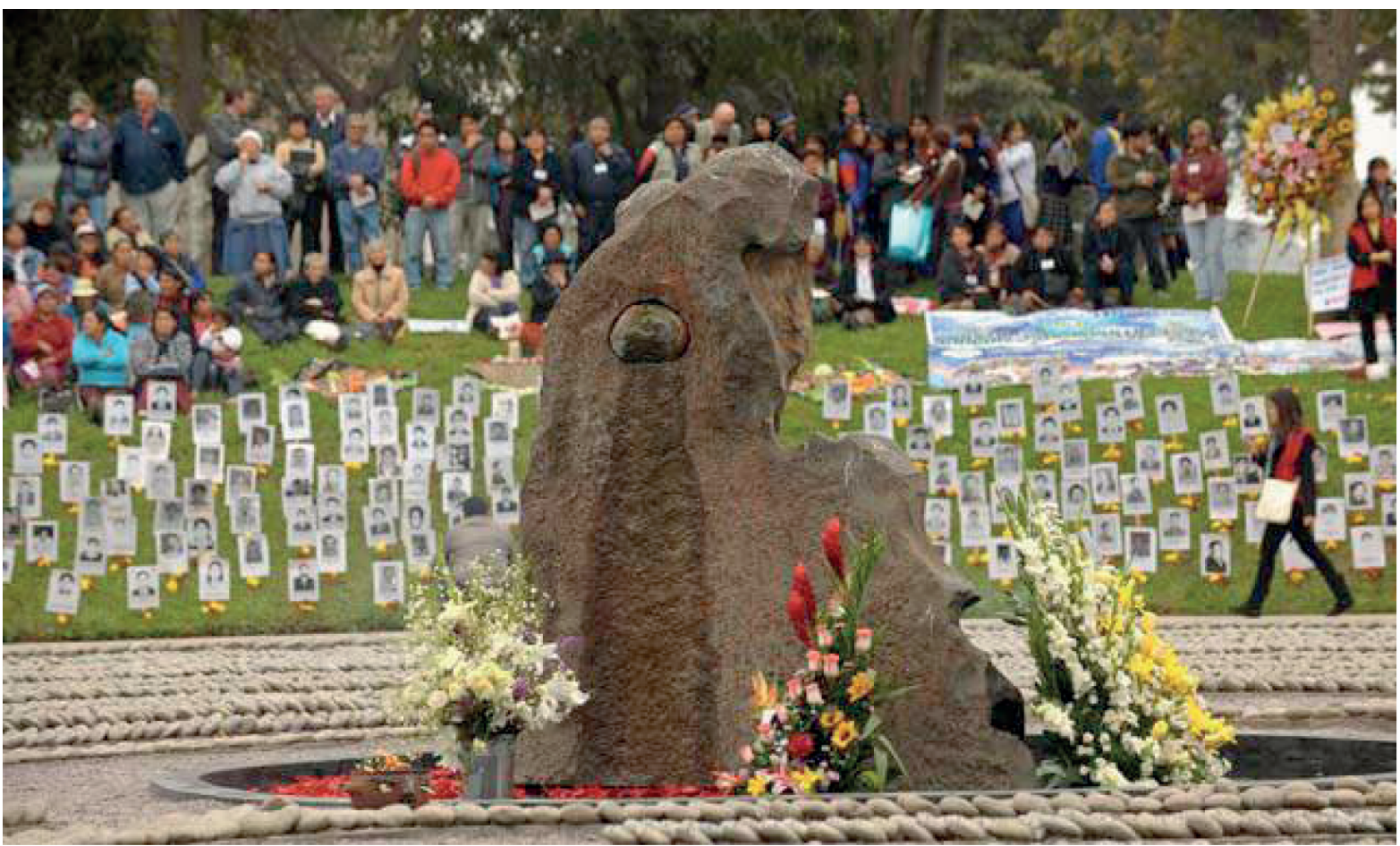

Fuente: http://www.larepublica.pe/28-08-2012/ceremonia-por-el-noveno-aniversario-de-la-cvr-se-desarrolla-frente-al-monumento-el-ojo-que-llora 


\section{Sentencia "Instituto de Reeducación del Menor" contra Paraguay}

El Instituto de Reeducación del menor "Pachito López" era un centro en el cual los menores de edad eran detenidos y recluidos por cometer delitos o actos contra la ley. La seguridad que debía ofrecerse a los menores fue menoscabada por abusos y actos contra ellos, donde los Derechos Humanos y a su vez los derechos del niño fueron obviados por las personas que deberían haber brindado una calidad de vida digna.

El hacinamiento fue una parte importante dentro de este conflicto, debido a que la sobrepoblación estaba superada en un $50 \%$ y esto permitió dentro de los recluidos el abuso sexual, además de falencias en los servicios públicos.

Por lo anterior, la CIDH realizó las siguientes consideraciones en cuanto son niños y niñas menores de 18 años las víctimas de estos hechos:

147. La Corte llama la atención que en el presente caso un significativo número de las violaciones alegadas tienen como presuntas víctimas a niños, quienes, al igual que los adultos, "poseen los derechos humanos que corresponden a todos los seres humanos [...] y tienen además derechos especiales derivados de su condición, a los que corresponden deberes específicos de la familia, la sociedad y el Estado"2. Así lo establece, por lo demás, el artículo 19 de la Convención Americana que dispone que "[t]odo niño tiene derecho a las medidas de protección que su condición de menor requiere por parte de su familia, de la sociedad y del Estado". Esta disposición debe entenderse como un derecho adicional, complementario, que el tratado es-

2 Condición Jurídica y Derechos Humanos del Niño. Opinión Consultiva OC-17/02 de 28 de agosto de 2002. Serie A No. 17, párr. 54. tablece para seres que por su desarrollo físico y emocional necesitan de protección especial ${ }^{3}$.

Por su parte en cuanto a la responsabilidad del Estado frente a las personas privadas de la libertad la Corte considera:

152. Frente a las personas privadas de libertad, el Estado se encuentra en una posición especial de garante, toda vez que las autoridades penitenEl hacinamiento ciarias ejercen un fuerte control o dominio sofue una parte bre las personas que se encuentran sujetas a su custodiat. De este modo, se produce una relación e interacción especial de sujeción entre la persona privada de libertad y el Estado, caracterizada por la particular intensidad con que el Estado puede regular sus derechos $y$ obligaciones y por las circunstancias propias del importante dentro de este conflicto, debido a que la sobrepoblación estaba superada en un $50 \%$ y esto permitió dentro de los recluidos el abuso sexual, además de falencias en los servicios públicos. encierro, en donde al recluso se le impide satisfacer por cuenta propia una serie de necesidades básicas que son esenciales para el desarrollo de una vida digna. (...)

160. En materia de derecho a la vida, cuando el Estado se encuentra en presencia de niños privados de libertad, como ocurre mayormente en

3 Cfr. Condición Jurídica y Derechos Humanos del Niño, supra nota 150, párr. 54; y Caso de los Hermanos Gómez Paquiyauri, supra nota 26, párr. 164.

4 Cfr. Caso de los Hermanos Gómez Paquiyauri, supra nota 26, párr. 98; Caso Juan Humberto Sánchez. Sentencia de 7 de junio de 2003. Serie C No. 99, párr. 111; y Caso Bulacio, supra nota 56, párr. 138. En el mismo sentido, cfr. Caso de la Cárcel de Urso Branco, supra nota 54, considerando sexto; y Caso de los Hermanos Gómez Paquiyauri. Medidas Provisionales. Resolución de la Corte Interamericana de Derechos Humanos de 7 de mayo de 2004, considerando décimo tercero. 


El Estado debe
hacerse participe
activo de los
problemas de salud
de sus encarcelados
sea por enfermedad
general o falta de
higiene en los Centros
Penitenciarios, por
cuanto es él quien
toma la tutela de los
procesados cuando
se presume su
participación en la
criminalidad.

el presente caso, tiene, además de las obligaciones señaladas para toda persona, una obligación adicional establecida en el artículo 19 de la Convención Americana. Por una parte, debe asumir su posición especial de garante con mayor cuidado y responsabilidad, $y$ debe tomar medidas especiales orientadas en el principio del interés superior del niño ${ }^{5}$. Por otra, la protección de la vida del niño requiere que el Estado se preocupe particularmente de las circunstancias de la vida que llevará mientras se mantenga privado de libertad, puesto que ese derecho no se ha extinguido ni restringido por su situación de detención o prisión (supra párr. 159).

161. En este sentido, los artículos 6 y 27 de la Convención sobre los Derechos del Niño incluyen en el derecho a la vida la obligación del Estado de garantizar "en la máxima medida posible la supervivencia y el desarrollo del niño". El Comité de Derechos del Niño ha interpretado la palabra "desarrollo" de una manera amplia, holística, que abarca lo físico, mental, espiritual, moral, psicológico y social'. Mirado así, un Estado tiene, respecto de niños privados de libertad $y$, por lo tanto, bajo su custodia, la obligación de, inter alia, proveerlos de asistencia de salud y de educación, para así asegurarse de que la detención a la que

5 Cfr. Caso de los Hermanos Gómez Paquiyauri, supra nota 26, párrs. 124, 163-164, y 171; Caso Bulacio, supra nota 56, párrs. 126 y 134; y Caso de los "Niños de la Calle" (Villagrán Morales y otros), supra nota 152, párrs. 146 y 191. En el mismo sentido, cfr. Condición Jurídica y Derechos Humanos del Niño, supra nota 150, párrs. 56 y 60.

6 Comité de los Derechos del Niño de las Naciones Unidas, Observación General No. 5 de 27 de noviembre de 2003, párrafo 12. los niños están sujetos no destruirá sus proyectos de vida. (...).

170. De este modo, la Corte puede concluir que en ningún momento existieron en el Instituto las condiciones para que los internos privados de libertad pudieran desarrollar su vida de manera digna, sino más bien a éstos se los hizo vivir permanentemente en condiciones inhumanas y degradantes, exponiéndolos a un clima de violencia, inseguridad, abusos, corrupción, desconfianza y promiscuidad, donde se imponía la ley del más fuerte con todas sus consecuencias. Al respecto, valga recordar lo señalado por el Juez de Primera Instancia en lo Civil y Comercial de Noveno Turno, al resolver el hábeas corpus genérico interpuesto a favor de los internos del Instituto (supra párr. 134.28), en el sentido de que en éste "se halla[ba]n acreditados los presupuestos de a) violencia física, psíquica o moral que agrava las condiciones de detención de las personas privadas de libertad; [y] b) la amenaza a la seguridad personal de los menores internos". (...)

230. En el caso de privación de libertad de niños, la regla de la prisión preventiva se debe aplicar con mayor rigurosidad, ya que la norma debe ser la aplicación de medidas sustitutorias de la prisión preventiva. Dichas medidas pueden ser, inter alia, la supervisión estricta, la custodia permanente, la asignación a una familia, el traslado a un hogar o a una institución educativa, así como el cuidado, las órdenes de orientación y supervisión, el asesoramiento, la libertad vigilada, los programas de enseñanza y formación profesional, y otras posibilidades alternativas a la internación en instituciones $^{7}$. La aplicación de estas medidas sustitutorias tiene la finalidad de asegurar que los niños sean tratados de manera adecuada y proporcional a sus circunstancias y a la infracción ${ }^{8}$. Este precepto está regulado en diversos instrumentos y reglas internacionales.

\footnotetext{
Cfr. Artículo 40.4 de la Convención sobre los Derechos del Niño.

8 Supra nota 192.
} 


\section{RESULTADOS Y CONCLUSIONES}

Dentro del contexto del Sistema Carcelario se denota que las políticas públicas no llevan a minimizar la criminalidad por cuanto las soluciones que propende el Estado es la creación de más centros penitenciarios, en cambio de lograr educar y fortalecer el ámbito formador y generador de violencia que permite el aumento conmensurado de la criminalidad.

Existe una ineficacia del programa de resocialización por parte del Estado, por cuanto las garantías pertinentes que se deben brindar para la transformación de los reos, apartándose del contexto criminal a la luz de una debilidad institucional y de un personal no idóneo para el tratamiento, fomenta un desmesurado acrecentamiento de conductas propias para delinquir dentro y fuera del Sistema.

El Estado debe hacerse partícipe activo de los problemas de salud de sus encarcelados, sea por enfermedad general o falta de higiene en los Centros Penitenciarios, por cuanto es él quien toma la tutela de los procesados cuando se presume su participación en la criminalidad.

\section{REFERENCIAS BIBLIOGRÁFICAS}

ANITUA, Gabriel Ignacio (2011). Castigo, cárceles y controles. Ediciones Didot, Buenos Aires. Argentina

BALESTENA, Eduardo (2006). La Fábrica Penal, visión interdisciplinaria del Sistema Punitivo. Editorial B de F. Montevideo, Uruguay.

BECCARIA, Cesare (1968). De los delitos y las Penas. Alianza Editorial. Madrid, España.

BERGALLI, Roberto (2001). Globalización y control social: Postfordismo y control punitivo. Sistema $\mathrm{N}^{\circ}$ 160. Madrid, España.

(1976). ¿Readaptación social por medio de la ejecución penal? Universidad Complutense. Madrid, España.

BUSTOS R., Juan (1987). Pena privativa de la libertad y política criminal: los establecimientos de máxima seguridad. Control Social y Sistema Penal, PPU Barcelona.

COHEN, Stanly (1988). Visiones del Control Social. PPU. Traducido por Elena Larrauri. Barcelona, España.

CORREA, Henao Magdalena (2003). La limitación de los Derechos Fundamentales. Universidad Externado de Colombia. Bogotá, Colombia.

DE SOUSA Santos, Boaventura. (1991). Estado, Derecho y Luchas Sociales. ILSA. Bogotá, Colombia.

FOUCAULT, Michel (1994). Vigilar y castigar. Traducido por A. Garzón del Camino. Editorial siglo XXI.

GARCÍA Ramírez, Sergio (1975). La Prisión. Fondo de Cultura Económica. México.

(1982). Estudios de Derecho Penitenciario. Tecnos. Madrid, España.

(1999). Castigo y Sociedad Moderna. siglo XXI Editores. México.

HUERTAS D., Omar (2012). La Colonia Penal de Oriente. Último rezago del positivismo jurídico penal. Revista Diálogos de Saberes $N^{\circ} 35$. Universidad Libre. Bogotá, Colombia

MARTíNEZ, Mauricio (1995) Estado de Derecho y Política Criminal. Ediciones Jurídicas Gustavo Ibáñez. Bogotá, Colombia.

MELOSSI, Darío y Massimo, Pavarini (1987). Cárcel y fábrica. Traducido por X. Massimi. Siglo XXI Editores. México.

MORRIS, Norval (1978). El futuro de las Prisiones. Siglo XXI Editores. México.

MUÑAGORRI, Ignacio (1977). Sanción penal y política Criminal. Confrontación con la Nueva defensa social. Editorial Reus. Madrid, España.

(1997). Reflexiones sobre la pena de prisión en el Nuevo Código Penal de 1995: Polifuncionalidad e incremento regresivo de la comple- 
jidad penal. En Dobón, Juan y Rivera, Iñaki, secuestros institucionales y Derechos Humanos: la cárcel y el manicomio como laberintos de obediencias fingidas. Editorial Bosh. Barcelona.

PAVARINI, Massimo (1999). La miseria del reformismo penitenciario. Introducción a Rivera, Iñaki y Salt, Marcos. Los derechos fundamentales de los reclusos. España y Argentina. Editores del Puerto. Buenos Aires.

SALT, Marcos (1999). Los derechos fundamentales de los reclusos en Argentina. En Rivera, Iñaki y Salt Marcos. Los Derechos Fundamentales de los Reclusos. Editores del Puerto. Buenos Aires, Argentina.

SANDOVAL Huertas, Emiro (1984). Penología. Parte Especial. Universidad Externado de Colombia. Bogotá, Colombia.
TENORIO Tagle, Fernando (2002). El Sistema de Justicia penal en México. Fondo de Cultura Económica. México.

\section{WEBGRAFÍA}

http://azalearobles.blogspot.com/2012/04/hacinamiento-carcelario-en-colombia.html

http://www.corporacionavre.org/files/pdf/informetortura09.pdf

http://www.corteconstitucional.gov.co/ relatoria/2012/t-175-12.htm

http://www.inpec.gov.co/portal/page/portal/Inpec/ SeccionInpeccomoinstitucion/Consolidado_estadistico

http://www.corteidh.or.cr/

http://www2.ohchr.org/spanish/law/reclusos.htm 